\title{
Distribution of nitrogenous nutrients and denitrifiers strains in estuarine sediment profiles of the Tanshui River, northern Taiwan
}

\author{
L.F. Fan ${ }^{\text {a,b }}$, W.Y. Shieh ${ }^{\text {a }}$, W.F. Wu ${ }^{\text {c }}$, C.-P. Chen ${ }^{\text {b,d,* }}$ \\ a Institute of Oceanography, National Taiwan University, No. 1 Roosevelt Road, Sec. 4, Taipei 106, Taiwan \\ ${ }^{\mathrm{b}}$ Research Center for Biodiversity, Academia Sinica, No. 128 Academia Road, Sec. 2, Nankang, Taipei 115, Taiwan \\ ${ }^{\mathrm{c}}$ Graduate Institute of Agricultural Chemistry, National Taiwan University, No. 1 Roosevelt Road, Sec. 4, Taipei 106, Taiwan \\ ${ }^{\mathrm{d}}$ Institute of Fisheries Sciences, National Taiwan University, No. 1 Roosevelt Road, Sec. 4, Taipei City 106, Taiwan
}

Received 14 September 2005; accepted 16 May 2006

Available online 11 July 2006

\begin{abstract}
Chemical profiles of both oxidized (nitrate and sulfate) and reduced (ammonium, sulfide, acid-volatile sulfide [AVS], and pyrite) materials and the corresponding distribution of denitrifier microbial communities were measured at low tide in sediments at Guandu in the estuary of the Tanshui River, northern Taiwan in August 2002. Denitrifier strains were isolated for physiological and phylogenic analyses. Based on the distribution of nitrogenous compounds and denitrifier abundances, the vertical profile of Guandu sediments could be separated into four layers: a mixed layer (the top $1 \mathrm{~cm}$ of depth, respectively containing $0.82-2.37$ and $535.9-475.0 \mu \mathrm{M}$ of nitrate and ammonium), a nitrate-concentrated layer (1-5 cm in depth, 2.37-0.53 and 475.0-1192.1 $\mu \mathrm{M}$, respectively), a denitrifier-aggregation layer $(5-7 \mathrm{~cm}$ in depth, $0.53-0.72$ and 1192.1-1430.1 $\mu \mathrm{M}$, respectively), and an ammonium-enriched layer (7-12 cm in depth, 0.72-0.78 and 1430.1-2196.6 $\mu \mathrm{M}$, respectively). Denitrifier strains were detected in all layers except for the mixed layer. A variety of metabolic processes by these strains may occur in different layers. Bacillus jeotgali-, Bacillus sphaericus-, and Bacillus firmus-related strains isolated from the nitrate-concentrated layer may be involved in the nitrification-denitrification coupling process due to the relatively low nitrate concentrations (maximum $=2.37 \mu \mathrm{M}$ ), and may contribute to denitrification not nitrification. Bacillus bataviensis- and B. jeotgali-related strains isolated from the denitrifier-aggregation layer comprised the predominant denitrifier population $\left(3.64 \times 10^{4}\right.$ cells/g of denitrifier abundance). They possess the ability of dissimilatory nitrate reduction to ammonium (DNRA). Bacillus jeotgali-related strains and two newly identified strains of GD0705 and GD0706 isolated from the ammonium-enriched layer possibly use fermentative processes as the main metabolic pathway instead of denitrification when nitrate is scarce, and this further supports the high ammonium concentrations (up to $2.20 \mathrm{mM}$ ) found in the Guandu sediments. In addition, spore formation also enhances the chance of survival of these strains in the face with such a nitrate-deficient environment.
\end{abstract}

(C) 2006 Elsevier Ltd. All rights reserved.

Keywords: nitrogenous nutrients; denitrifier; sediment; Bacillus; Tanshui River

\section{Introduction}

In aquatic environments, both biological and chemical processes consume residual organic matter in sediments. Many organic compounds are efficiently and completely degraded by most heterotrophic organisms under oxic conditions. But

\footnotetext{
* Corresponding author.

E-mail addresses: lan@gate.sinica.edu.tw (L.F. Fan), zocp@ccvax.sinica. edu.tw (C.-P. Chen).
}

when dissolved oxygen is depleted, a large proportion of the organic compounds is metabolized anaerobically by microbial activities. The microbial community plays important roles in the degradation of organic compounds (e.g., Canfield et al., 2005). A general characteristic of organic carbon oxidation in sediments is the occurrence of zones with a predominant mode of respiration. Thermodynamic calculations indicate a progressively lower energy yield for organic matter decomposition coupled to respiration using various potential electron acceptors in the order of $\mathrm{O}_{2}>\mathrm{NO}_{3}^{-}>\mathrm{MnO}_{2}>\mathrm{FeO}(\mathrm{OH})>$ $\mathrm{SO}_{4}^{2-}>\mathrm{CO}_{2}$ (Capone and Kiene, 1988; Canfield et al., 
2005). Due to an unlimited source of sulfate from seawater, sulfate reduction on average accounts for at least half of the total carbon respiration in organic-rich sediments of coastal embayments and estuaries (e.g., Capone and Kiene, 1988).

Nitrate, although a thermodynamically favorable electron acceptor, does not appear to support a significant fraction of carbon oxidation due to its low concentrations in overlying waters and interstitial water (e.g., Nedwell et al., 1999). However, with heavy nitrate loading from external sources, nitrate respiration and denitrification may become important factors in the carbon cycling of sediments (Capone and Kiene, 1988). Denitrification involves the reduction of nitrate, via nitrite and nitric oxide, to nitrous oxide or dinitrogen gas under oxygen-limited conditions (Zumft, 1992). Thus, as an aquatic system gradually becomes hypoxic, the denitrification rate dramatically increases in the sediment, which means that the entire system budget of nutrients is overloaded.

Nitrogenous nutrient mineralization in sediments occurs through a series of processes including ammonification of organic matter, nitrification of ammonium, and reduction of nitrate through either denitrification or dissimilatory nitrate reduction to ammonium (e.g., An and Gardner, 2002). A new pathway of the nitrogen cycle recently described, the anammox process (Thamdrup and Dalsgaard, 2002), also contributes to nitrogen gas production in marine sediments. Denitrification appeared to be competitively more successful for nitrate at relatively high nitrate concentrations (Nedwell et al., 1999). Nitrification and denitrification can occur as a coupled process in surface sediments (Rysgaard et al., 1993).

Denitrifying bacteria are phylogenetically diverse and constitute about $20 \%$ of the bacterial population in sediments; they are capable of anaerobic growth (Tiedje, 1988). They belong to all major physiological groups except for the Enterobacteriaceae, which are obligate anaerobes, and Gram-positive bacteria other than Bacillus spp. (Zumft, 1992). Defined as a physiological group, denitrifiers as facultative anaerobes, which generally use oxygen respiration as the main metabolic pathway, can switch from oxygen to nitrogen oxides as terminal electron acceptors when subjected to anoxic conditions, such as in soils or estuarine sediments (Weier and MacRae, 1992; Zumft, 1992). In addition, most of the strains isolated from soils with denitrifying activities, such as Bacillus strains, are involved in nitrification-denitrification processes in soils, sediments, and soil treatment systems (Nedwell et al., 1999; Kim et al., 2005), and some strains isolated from freshwater sediments, like Pseudomonas strains, have the capacity for long-term survival without nitrate by carrying on a low level of fermentation (Tiedje, 1988).

In Taiwan, 6 million people, over a quarter of Taiwan's entire population, reside in the basin of the Tanshui River system. The estuary of the Tanshui River receives both treated and untreated domestic sewage discharges (Wu, 1999). The average concentration of inorganic nitrogen was $14.29 \mu \mathrm{M}$ in 2000-2002, and approximately $7400 \mathrm{tn}^{-\mathrm{ear}^{-1}}$ inorganic nitrogen is discharged from the Tanshui River into the Taiwan Strait (S.C. Pai, unpublished report). Ammonium is the predominant nitrogenous species in the estuary with concentrations ranging from 10 to $1000 \mu \mathrm{M}$, which is near the toxic level for most aquatic life forms (Wu, 1999; Jiann et al., 2005). Denitrification was observed in mangrove soil in an estuary of the Tanshui River (Chiu et al., 2004), and the highest rate occurred in the surface soil, and it then rapidly declined from the surface to lower layers. The abundance of denitrifiers ranges from $10^{4}$ to $10^{5}$ cells (g wet weight) ${ }^{-1}$ using the most probable number (MPN) method in mangrove soil (W.Y. Shieh, unpublished data).

Neither denitrifiers nor nitrogenous-related nutrients have been examined in the vertical profile of sediments in the estuary of the Tanshui River. The purpose of this study was to determinate the vertical profiles of oxidized (nitrate and sulfate) and reduced (ammonium, sulfide, acid-volatile sulfide [AVS], and pyrite) compound concentrations in the interstitial water or sediments, and the corresponding distributions of denitrifier microbial communities in the sediments of Guandu in the estuary of the Tanshui River. The denitrifier strains were isolated for physiological and phylogenic analyses. An integrated ecological view was synthesized among biogeochemical, microbial, and molecular microbial data to better understand the fate of nitrogenous nutrients under such complex conditions.

\section{Materials and methods}

\subsection{Study site}

The Tanshui River, located on the northwestern edge of Taipei City, contains the largest estuary in northern Taiwan (Fig. 1). The main tributaries of the Tanshui River are the Tahan, Hsintien, and Keelung Rivers. The downstream reaches of all three tributaries are tidally influenced. These rivers receive sewage discharges and waste effluents from the Taipei metropolitan area; the upper estuary is suboxic and the lower estuary becomes gradually oxic, because of tidal seawater intrusion (Jiann et al., 2005). Semidiurnal tides are the principal tidal constituents, with a mean tidal range of $2.22 \mathrm{~m}$ and a spring tidal range of $3.1 \mathrm{~m}$. In addition to the barotropic

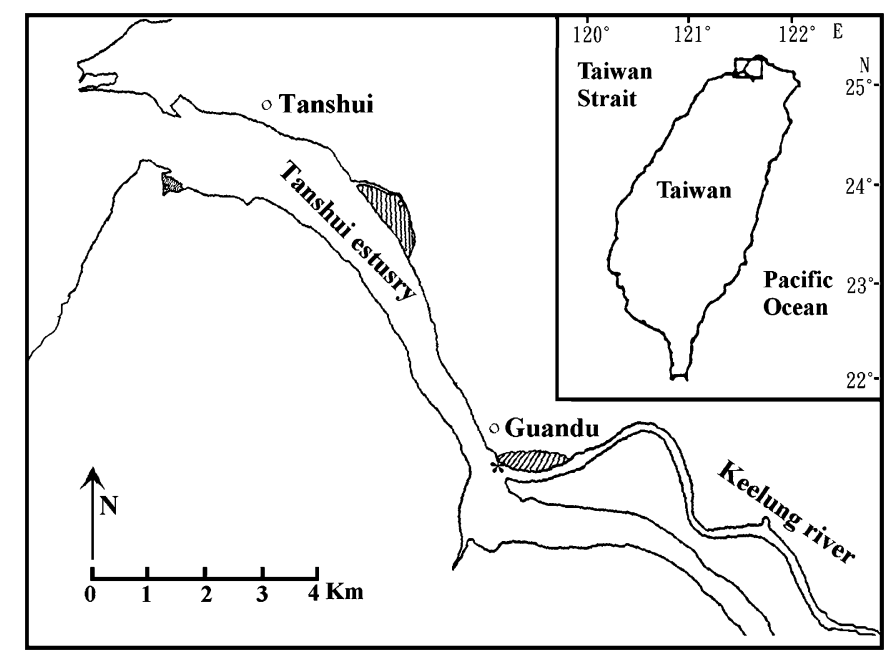

Fig. 1. Location of the estuary of the Tanshui River in northern Taiwan. 
flows forced by tides and river discharges, the baroclinic flow forced by seawater intrusion is another important transport mechanism in this estuarine system (Liu et al., 2002).

Guandu is located in the upper estuary where the Keelung River meets the main channel of the Tanshui River (Fig. 1). Sewage discharges from upstream and seawater intrusion mix here. The annual average concentrations for dissolved oxygen (DO) and nitrogenous compounds were $2.6 \pm 0.5 \mathrm{mg} \mathrm{L}^{-1} \mathrm{DO}$, $24.19 \pm 4.84 \mu \mathrm{M} \mathrm{NO}_{3}^{-}, 1.74 \pm 0.43 \mu \mathrm{M} \mathrm{NO}_{2}^{-}$, and $253.33 \pm$ $60 \mu \mathrm{M} \mathrm{NH} \mathrm{NH}_{4}^{+}(\mathrm{Wu}, 1999)$. Water salinity near Guandu varies from 9.5 to 29.5 psu with a tidal effect (Liu et al., 2002). The DO rose from $1.6 \mathrm{mg} \mathrm{L}^{-1}$ at low tide to $7.5 \mathrm{mg} \mathrm{L}^{-1}$ at high tide, whereas dissolved inorganic nitrogen (DIN) was diluted, decreasing from 638.57 to $284.29 \mu \mathrm{M} N$ during sampling carried out in 1999 (L.F. Fan, unpublished data). In addition, during the tidal circle, with the DO carried by the seawater, ammonium in the water column gradually decreases and becomes oxidized first to nitrite and then to nitrate (Jiann et al., 2005). The distribution of tidally averaged suspended sediment concentrations at Guandu site exhibits a local maximum, and sediment concentrations in bottom water may be twice as high of those in the upstream reaches (Liu et al., 2002).

Sediments in the upper $5 \mathrm{~cm}$ in depth at Guandu are very fine to medium sand (with ranges of $0.079-0.136 \mathrm{~mm}$ for particle size and $10.14-37.81 \%$ for silt/clay content) and are moderately to poorly sorted (with a range of $0.646-1.300$ for the sorting coefficient) (Hsieh, 1995). The total organic carbon content (TOC) ranged from $0.57 \%$ to $0.86 \%$, and the total nitrogen content (TN) was from $0.04 \%$ to $0.07 \%$ (Hsieh, 1995). In addition, the particle size was statistically higher in summer (August) than in autumn (November) and winter (January), whereas the TOC was statistically higher in winter than in spring (April) and summer (H.L. Hsieh, unpublished data).

\subsection{Sample collection}

Samples were collected at low tide at Guandu on August 12, 2002. Sediment samples were taken using plastic tubes with an internal diameter of $9.6 \mathrm{~cm}$ for analysis of environmental parameters and another three tubes with an internal diameter of $7.0 \mathrm{~cm}$ for the microbial communities. Samples for environmental parameters were stored in an iced cooler and carried back to the laboratory. Twelve-centimeter-long cores were sectioned in 0.5 - or $1.0-\mathrm{cm}$ intervals in an argon (Ar)filled glove bag (Ar-rich, oxygen-free environment), and no signs of bioturbators were found. A set of subsamples was centrifuged at $4000 \mathrm{rpm}$ for $15 \mathrm{~min}$ and filtered through a $0.45-\mu \mathrm{m}$ Nuclepore filter to obtain the interstitial water, which was used for determining salinity, nitrate, ammonium, and sulfate, while the solid phase was used for organic and sulfur compound analyses. Samples for the microbial community analysis were stored at $4{ }^{\circ} \mathrm{C}$, and were cultured within 1 day.

\subsection{Analysis of environmental parameters}

Interstitial water: Salinity was determined using a refractometer (S/Mill-E, ATAGO, Tokyo, Japan). Nitrate $\left(\mathrm{NO}_{2}^{-}+\right.$
$\mathrm{NO}_{3}^{-}$) was determined by reducing nitrate to nitrite, and then identifying nitrite by means of the pink azo dye method using a flow injection analyzer with an on-line cadmium $(\mathrm{Cd})$ coil (Pai and Riley, 1994). Ammonium was measured using the indophenol blue (IPB) method (Pai et al., 2001). Sulfate was determined by ion chromatography (O'Dell et al., 1984) with a Dionex 4500I ion chromatograph (AIR, Golden, CO) equipped with a conductivity detector and an IonPac AS4A anion exchange column (AIR). Sulfide was measured using the methylene blue method (Cline, 1969).

Solid phase: Pyrite-S was determined using the $\mathrm{Cr}(\mathrm{II})+$ $6 \mathrm{~N} \mathrm{HCl}$ extraction method, and acid-volatile sulfide (AVS) was measured using the cold $6 \mathrm{~N} \mathrm{HCl}$ extraction technique (Canfield et al., 1986). Total organic carbon (TOC) and total nitrogen (TN) contents were determined using a CHN analyzer (Perkin Elmer EA 2400 Series II; Wellesley, MA) after the samples had been freeze-dried and acid-fumed.

\subsection{Determination of microbial communities}

The addition of an extra nitrate source coupled with the most-probable-number (MPN) method has been widely used for culture and enumeration of denitrifier abundances (Weier and MacRae, 1992; Shieh et al., 2004). To obtain viable heterotrophic bacteria, and determine denitrifying bacteria abundances and subsequent denitrifying strains, we used PYN broth (with an extra nitrate source and media containing the following in $\mathrm{g} \mathrm{L}^{-1}$ of distilled water: polypeptone [Diago, Toyko, Japan], 3; Bacto-yeast extract, $1 ; \mathrm{NaCl}, 20 ; \mathrm{KNO}_{3}, 2$; $\mathrm{MgCl}_{2} \cdot 6 \mathrm{H}_{2} \mathrm{O}, 2 ; \mathrm{CaCl}_{2}, 0.005 ; \mathrm{CuCl}_{2} \cdot 2 \mathrm{H}_{2} \mathrm{O}, 0.005$; $\mathrm{FeCl}_{3} \cdot 6 \mathrm{H}_{2} \mathrm{O}, 0.005 ; \mathrm{Na}_{2} \mathrm{MoO}_{4} \cdot 7 \mathrm{H}_{2} \mathrm{O}, 0.005$; and MOPSO [3-(N-morpholino)-2-hydroxyl-propanesulfonic acid, a kind of biological buffer], 4.5) for the MPN method (Shieh et al., 1989). Two grams of wet mass of each subsample was vigorously shaken in $50 \mathrm{ml}$ of $4.5 \%$ MOPSO buffer containing $2 \%$ $\mathrm{NaCl}$. The shaken solutions were decimally diluted with the same buffer. The various dilutions of these samples were used for bacterial enumeration. Portions $(1 \mathrm{ml})$ of the appropriate decimal dilutions of various samples were transferred to rimless tubes containing PYN medium $(5 \mathrm{ml})$; a Durham insert (for gas collection) was placed in an inverted position in each tube. All cultures were incubated anaerobically (using anaerobic jars) at $25{ }^{\circ} \mathrm{C}$ in the dark for 14 days. It is generally thought that gas produced from such culture conditions is either nitrogen or nitrous because of denitrification (e.g., Weier and MacRae, 1992). Gas production (which accumulated in the Durham inserts) and visible turbidity development were the respective criteria used for MPN estimation of denitrifying and heterotrophic bacteria. All MPN values obtained were estimated by the 3-tube inoculation method (Shieh et al., 1989).

The MPN cultures considered positive (i.e., with gas production) for denitrifying bacteria were transferred (one loopful) to fresh PYN broth medium $(5 \mathrm{ml})$ for a secondary enrichment cultivation. The secondary enrichment cultures with gas production were streaked (one loopful) onto PY agar plates (with the medium containing the following in $\mathrm{g} \mathrm{L}^{-1}$ of distilled water: polypeptone, 3; Bacto-yeast extract, 
1; $\mathrm{NaCl}, 20 ; \mathrm{MgCl}_{2} \cdot 6 \mathrm{H}_{2} \mathrm{O}, 2 ; \mathrm{CaCl}_{2}, 0.005 ; \mathrm{CuCl}_{2} \cdot 2 \mathrm{H}_{2} \mathrm{O}$, $0.005 ; \mathrm{FeCl}_{3} \cdot 6 \mathrm{H}_{2} \mathrm{O}, 0.005 ; \mathrm{Na}_{2} \mathrm{MoO}_{4} \cdot 7 \mathrm{H}_{2} \mathrm{O}, 0.005$; and Bacto agar [Difco, Franklin Lakes, NJ], 7.5), and the plates were incubated at $25{ }^{\circ} \mathrm{C}$ under aerobic conditions. Colonies of 1-3 predominant types appearing on each plate were collected and purified by successive streaking on PY agar plates. All isolates that again produced gas in PYN broth were kept in PY stab medium (containing the following in $\mathrm{g} \mathrm{L}^{-1}$ of distilled water: polypeptone, 3; Bacto-yeast extract, $1 ; \mathrm{NaCl}, 20$; $\mathrm{KNO}_{3}, 2 ; \mathrm{MgCl}_{2} \cdot 6 \mathrm{H}_{2} \mathrm{O}, 2 ; \mathrm{CaCl}_{2}, 0.005 ; \mathrm{CuCl}_{2} \cdot 2 \mathrm{H}_{2} \mathrm{O}$, $0.005 ; \mathrm{FeCl}_{3} \cdot 6 \mathrm{H}_{2} \mathrm{O}, 0.005 ; \mathrm{Na}_{2} \mathrm{MoO}_{4} \cdot 7 \mathrm{H}_{2} \mathrm{O}, 0.005$; and Bacto agar, 7.5) at $20{ }^{\circ} \mathrm{C}$ and were subcultured at intervals of 2-3 months.

\subsection{Isolate characterization}

The Gram reaction, and oxidase and catalase concentrations were determined according to the procedures of Shieh et al. (1989) after growth for 1-2 days on PY agar plates. Carbohydrate (adonitol, cellobiose, glucose, inositol, lactose, mannose, melbiose, and sucrose) fermentations were tested by inoculating 1 loopful of culture into each of the fermentation media ( $5 \mathrm{ml}$, stab type). Cultures were examined daily for color change for up to 7 days. Amylase was tested according to the procedure of Shieh et al. (1989). Cell growth for 12 days in PY broth media was observed for motility by phase-contrast microscopy.

\subsection{DNA extraction and PCR amplification of $16 S$ rDNA}

Genomic DNA from pure cultures was obtained using a PUREGENE DNA Isolation Kit (Gentra, Minneapolis, $\mathrm{MN}$ ) following the instructions of the manufacturer. PCR amplifications of bacterial 16S rDNA from DNA extracts were performed with a total volume of $50 \mathrm{ml}$ in a model 9600 thermal cycler (Perkin-Elmer Cetus, Norwalk, CT). Primer pairs used for amplification of eubacterial 16S rDNA were 5'AGAGTTTGATCMTGGCTCAG- $3^{\prime}$ and $5^{\prime}$-CGGTTACCTTG TTAGGACTTCACC-3' (positions 8-27 [16F27] and 14881511 [16R1488] of the Escherichia coli numbering system) as described by Bennasar et al. (1998). Two hundred nanograms of total genomic DNA extract was amplified in reaction mixtures containing $10 \mathrm{pmol}$ of each primer, $200 \mathrm{mM}$ of each deoxyribonucleoside triphosphate, $150 \mathrm{mM} \mathrm{MgCl}$ (Promega, Madison, WI), $0.5 \mathrm{U}$ of Taq polymerase (Promega), and a 0.10 volume of a $10 \times$ PCR buffer provided with the enzyme. After a denaturation step of $10 \mathrm{~min}$ at $95^{\circ} \mathrm{C}$, amplification reactions were performed using 35 cycles of denaturation $(1 \mathrm{~min}$ at $\left.95^{\circ} \mathrm{C}\right)$, primer annealing $\left(1.5 \mathrm{~min}\right.$ at $\left.52^{\circ} \mathrm{C}\right)$, and primer extension $\left(2 \mathrm{~min}\right.$ at $\left.72^{\circ} \mathrm{C}\right)$, with a final extension step of $5 \mathrm{~min}$ at $72{ }^{\circ} \mathrm{C}$. PCR products were analyzed by electrophoresis on $1 \%\left(\mathrm{wt} \mathrm{vol}^{-1}\right)$ agarose gels (Viogene, Taipei, Taiwan), followed by $15 \mathrm{~min}$ of staining with ethidium bromide $\left(0.5 \mathrm{mg} \mathrm{L}^{-1}\right)$. Bands were visualized by UV excitation. The PCR products were checked for size and subsequently sequenced.

\subsection{Sequence and phylogenic analysis of isolated strains}

The PCR products were purified with a Clean Up-M kit (Viogene) as specified by the manufacturer. DNA sequences were determined by direct sequencing with a model 3730 DNA sequencer (Applied Biosystems, Foster City, CA) using dye terminator chemistry. The primers used for sequencing were $16 \mathrm{~F} 27$ and 16R1488.

Nucleotide sequences were aligned with sequences from the NCBI database; only homologous positions at which nucleotides were found in all sequences were included in the analysis (Thompson et al., 1997). Two strains were used as outgroups for analysis: one was a non-denitrifying strain isolated from this study (GD0402), and the other was a Gramnegative denitrifying strain isolated from a sponge ( $\mathrm{sp} 90$ ). Evolutionary distances, derived from sequence pair dissimilarities using the Jukes-Cantor algorithm (Jukes and Cantor, 1969), were calculated using the DNADIST program from the Phylogeny Inference Package (PHYLIP), version 3.573c (Felsenstein, 1989). Dendrograms were generated using the neighbor-joining and maximum likelihood methods of Puzzle version 3.5. Consensus trees were calculated after bootstrapping (using 1000-replicate trees).

\section{Results}

\subsection{Sediment profiles of environmental parameters}

In the Guandu sediments, the interstitial water content decreased from $41.06 \pm 5.05 \%$ to $30.08 \pm 2.14 \%$ in the upper layer (the top $1 \mathrm{~cm}$ of depth), and then increased to $46.48 \pm 5.05 \%$ in the deeper layer (from 7 to $12 \mathrm{~cm}$ in depth) (Fig. 2a). Salinity in the interstitial water was low (12 \pm 0 $15 \pm 0 \mathrm{psu}, n=3$ ) in the upper layer because of flow mixing at ebb tides, and then was relatively constant at $18 \pm 0$ $21 \pm 0$ psu ( $n=3$, Fig. 2a) from the middle (from 1 to $7 \mathrm{~cm}$ in depth) to the deeper layer. The TOC content was relatively low $(0.60 \pm 0.20 \%-0.76 \pm 0.12 \%, n=3)$ in the upper layer and increased more than 2-fold in the deep layer (Fig. 2b). The same pattern of TOC content was found for the TN content profile (Fig. 2b).

Materials in the oxidized form were mainly composed of nitrate and sulfate. The concentration of nitrate in the interstitial water was lowest $(0.37 \pm 0.04-0.82 \pm 0.30 \mu \mathrm{M}, n=3)$ at the sediment-water interface, (with a maximum value of $2.37 \pm 0.36 \mu \mathrm{M}$ found in the upper layer) and was restricted to the top $5 \mathrm{~cm}$ of depth (Fig. 2c), whereas the concentration of sulfate penetrated deeper (to the deeper layer), and was greater (over 6000-fold) than nitrate in all sediment samples (Fig. 2c).

Relative to the oxidized forms, except for sulfide, other reduced compounds such as ammonium, AVS, and pyrite showed similar profiles in the sediments (Fig. 2d,e). Concentrations of ammonium in the interstitial water increased with depth (with a maximum value of $2196.6 \pm 184.14 \mu \mathrm{M}$ at a depth of $12 \mathrm{~cm}$, Fig. 2d). The same trends were found for the reduced sulfur compounds (AVS and pyrite, Fig. 2e). 
(a)

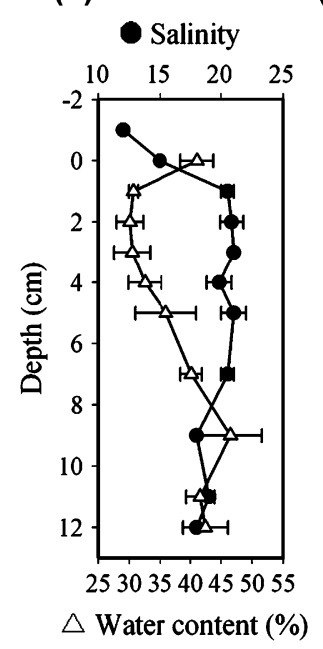

(b)

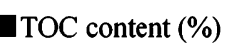

(c)

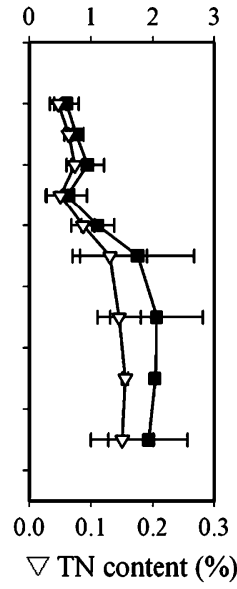

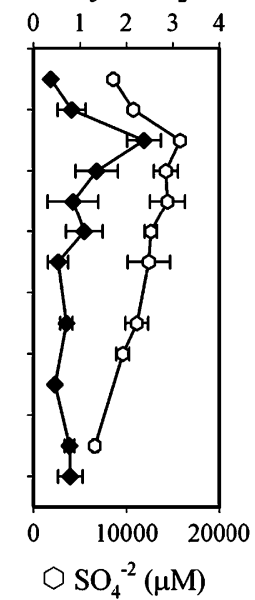

(d)

$\mathrm{ONH}_{4}^{+}(\mu \mathrm{M})$

$0 \quad 100020003000$

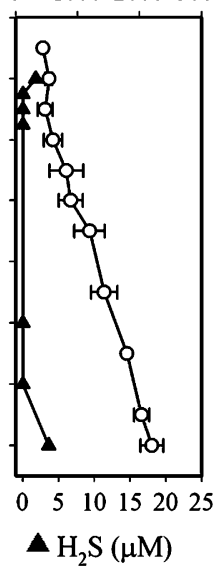

(e)

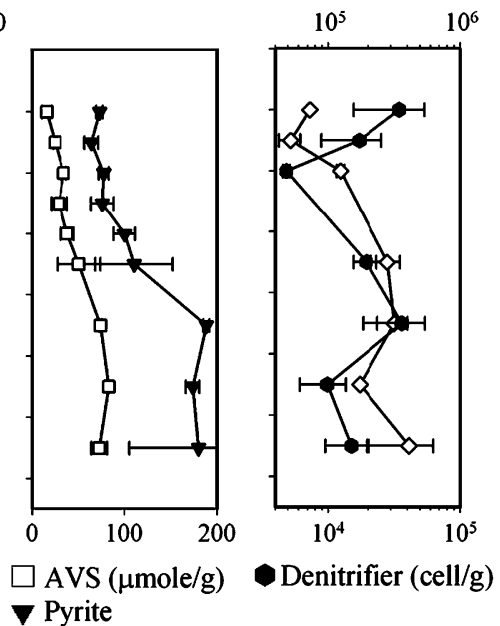

(f)

$\diamond$ Total bacteria (cell/g)

$10^{5} \quad 10^{6}$

Fig. 2. Vertical profiles of environmental factors in the Guandu sediments. (a) Salinity

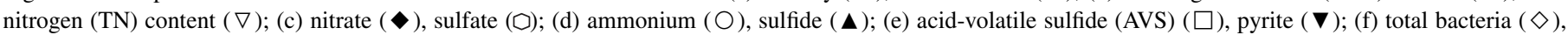
denitrifier ( ). $n=3$; bar, S.D.

However, concentrations of sulfide in the interstitial water were not detected, except at the sediment-water interface and at a depth of $12 \mathrm{~cm}$. With the exception of sulfide, other reduced compounds were significantly positively correlated with the organic content of the sediment (Table 1).

\subsection{Sediment profiles of viable bacteria}

Total viable bacterial abundances in the sediments generally increased with depth to a maximum value of $4.1 \times 10^{5}$ cells $\mathrm{g}^{-1}$ in the deeper layer (Fig. 2e), and were positively correlated with the organic content (Table 1). The profile of denitrifiers was not as regular as that of total viable bacteria, whereas the greatest abundances of denitrifiers appeared in the middle to deeper layers (at a depth of $7 \mathrm{~cm})\left(3.64 \times 10^{4}\right.$ cells $\mathrm{g}^{-1}$, Fig. 2e), at which the concentration of nitrate had diminished but sulfate was still abundant (Fig. 2c). However, there were no significant correlations between denitrifiers and any of the other environmental characteristics (Table 1).

Sixty-four strains were isolated from the MPN tubes which were capable of producing gas during the bacterial counts (i.e., they contained denitrifiers). Only 13 isolates did not lose their gas-producing ability in PYN broth medium after subculturing. Among the strains possessing denitrifying ability, 3 of them were isolated from the upper layer of sediment, 6 from the middle layer, and 4 from the deeper layer.

All 13 of the denitrifier strains were rod-shaped, and the colonies had generally smooth surfaces, were Gram-positive and spore-forming, and had catalase and oxidase activities. They were divided into seven groups, based on carbohydrate fermentation and amylase tests (Table 2). Among these seven groups, most of them used glucose and mannose for anaerobic fermentation except for group I. Moreover, groups II, III, and IV possessed no ability to utilize starch, group II did not use

Table 1

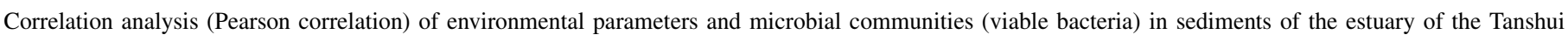

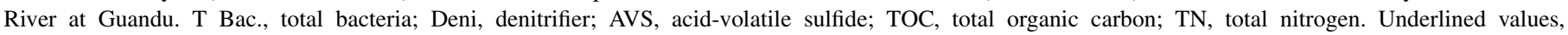
$p<0.05$; bold and underlined values, $p<0.01$

\begin{tabular}{|c|c|c|c|c|c|c|c|c|c|c|c|c|c|}
\hline & Salinity & $\mathrm{Cl}^{-}$ & $\mathrm{NO}_{3}^{-}$ & $\mathrm{SO}_{4}^{2-}$ & $\mathrm{NH}_{4}^{+}$ & $\mathrm{H}_{2} \mathrm{~S}$ & AVS & Pyrite & TOC & $\mathrm{TN}$ & $\mathrm{C} / \mathrm{N}$ & T Bac. & Deni \\
\hline Water & $-\underline{0.65}$ & -0.27 & $-\underline{0.64}$ & $-\underline{0.87}$ & 0.79 & 0.37 & 0.68 & 0.75 & 0.67 & 0.70 & 0.65 & 0.39 & 0.27 \\
\hline Salinity & & $\underline{0.92}$ & 0.48 & 0.61 & 0.06 & 0.65 & $\overline{0.10}$ & $-\overline{0.03}$ & $\overline{0.11}$ & 0.07 & -0.17 & 0.29 & -0.36 \\
\hline $\mathrm{Cl}^{-}$ & & & $\overline{0.39}$ & $\overline{0.53}$ & 0.30 & -0.79 & 0.02 & -0.14 & -0.01 & -0.04 & -0.31 & 0.05 & -0.33 \\
\hline $\mathrm{NO}_{3}^{-}$ & & & & 0.75 & $-\underline{0.47}$ & $\overline{0.66}$ & -0.55 & -0.58 & -0.56 & -0.57 & -0.41 & -0.58 & -0.20 \\
\hline $\mathrm{SO}_{4}^{2-}$ & & & & & $-\overline{0.63}$ & $\overline{0.51}$ & $-\mathbf{0 . 7 0}$ & $-\underline{0.79}$ & $-\underline{0.68}$ & $-\underline{0.72}$ & -0.58 & -0.66 & 0.10 \\
\hline $\mathrm{NH}_{4}^{+}$ & & & & & & $-\underline{0.85}$ & 0.94 & $\overline{0.93}$ & $\overline{0.90}$ & $\overline{0.92}$ & 0.56 & $\underline{0.83}$ & -0.12 \\
\hline $\mathrm{H}_{2} \mathrm{~S}$ & & & & & & & $-\overline{0.70}$ & $-\overline{\mathbf{0 . 7 9}}$ & $-\overline{0.72}$ & $-\overline{0.58}$ & -0.59 & $\overline{0.50}$ & -0.08 \\
\hline AVS & & & & & & & & $\overline{0.96}$ & $\overline{0.96}$ & 0.97 & 0.69 & 0.74 & -0.13 \\
\hline Pyrite & & & & & & & & & 0.94 & 0.94 & 0.73 & $\underline{0.80}$ & 0.10 \\
\hline TOC & & & & & & & & & & $\overline{1.00}$ & $\overline{0.80}$ & $\overline{0.82}$ & -0.03 \\
\hline $\mathrm{TN}$ & & & & & & & & & & & $\overline{0.78}$ & $\overline{0.81}$ & -0.06 \\
\hline $\mathrm{C} / \mathrm{N}$ ratio & & & & & & & & & & & & $\overline{0.68}$ & 0.33 \\
\hline Total bacteria & & & & & & & & & & & & & 0.08 \\
\hline
\end{tabular}


Table 2

List of physiological tests and character groupings of 13 isolated strains. + , positive; - , negative; $+/-$, either positive or negative

\begin{tabular}{|c|c|c|c|c|c|c|c|}
\hline & I $\left(1^{\mathrm{a}}\right)$ & II (2) & III (2) & IV (1) & $\mathrm{V}(1)$ & VI (5) & VII (1) \\
\hline Color & Beige & Beige & Beige & Beige & Light & Beige/white & White \\
\hline Surface texture & Smooth & Smooth & Smooth & Smooth & Rough & Smooth & Smooth \\
\hline Denitrifying & + & + & + & + & + & + & + \\
\hline Gram's reaction & + & + & + & + & + & + & + \\
\hline Catalase & + & + & + & + & + & + & + \\
\hline Oxidase & + & + & + & + & + & + & + \\
\hline Spore formation & + & + & + & + & + & + & + \\
\hline Moving & + & - & - & - & - & - & - \\
\hline Adonitol fermentation & - & - & - & + & + & - & - \\
\hline Cellobiose fermentation & - & - & + & + & + & + & - \\
\hline Glucose fermentation & - & + & + & + & + & + & + \\
\hline Mannose fermentation & - & + & + & + & + & + & + \\
\hline Melbiose fermentation & + & $+/-$ & $+I-$ & + & - & $+/-$ & + \\
\hline Sucrose fermentation & + & - & - & - & - & $+/-$ & + \\
\hline Inositol fermentation & - & - & - & - & - & - & + \\
\hline Lactose fermentation & - & - & - & - & - & - & - \\
\hline Amylase & - & - & - & - & + & + & + \\
\hline Arginine dihydrolase & - & - & $+/-$ & - & - & - & - \\
\hline Lysine decarboxylase & - & - & - & - & - & - & - \\
\hline Ornithine decarboxylase & - & - & - & - & - & - & - \\
\hline
\end{tabular}

a Number of strains included.

cellobiose, and group IV additionally used adonitol for acid production. Groups V, VI, and VII were all equipped with the ability to utilize starch; group V used adonitol and group VII used inositol for acid production.

\subsection{Sediment profiles of microbial strains}

The $16 \mathrm{~S}$ rDNA of the 13 strains was sequenced. The sequences of denitrifying bacteria isolated in this study have been deposited in the NCBI nucleotide sequence databases under accession numbers DQ084534-DQ084547. Similarities between each pair of the 13 strains were higher than 0.922 (Table 3). Based on the maximum likelihood analysis, they were divided into five clades (Fig. 3). Similarities between two of the five clades were higher than 0.978 (Table 3). Among these five clades, clade A included the strain closely related $(99.1 \%)$ to Bacillus sphaericus. Clade B included strains closely related $(98.6 \%)$ to Bacillus pichinotyi. Clade $\mathrm{C}$ included strains closely related to both Bacillus djibelorensis (99.4\% and $97.9 \%)$ and Bacillus bataviensis $(99.3 \%$ and $97.8 \%)$. Clade D included a strain closely related $(99.1 \%)$ to Bacillus firmus. Clade E, the largest group, included 7 strains closely related to Bacillus jeotgali (up to 99.5\%) (Table 3). All the highly related strains, except for B. sphaericus (Sneath, 1986), B. bataviensis (Heyrman et al., 2004), B. firmus (Sneath, 1986), and B. jeotgali (Yoon et al., 2001), have previously been published, while the others were only found on the NCBI database (available at http://www.ncbi.nlm.nih.gov/).

The physiological and phylogenic aspects of the isolated strains were compared. Physiological groups I, II, III, and IV were individually concordant with phylogenic clades A, $\mathrm{B}, \mathrm{C}$, and D, respectively, whereas physiological groups IV,

Table 3

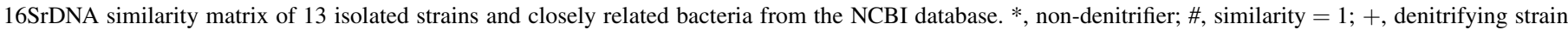
isolated from a sponge

\begin{tabular}{|c|c|c|c|c|c|c|c|c|c|}
\hline & GD1204 & GD1209 & GD0302 & GD0403 & GD1406 & GD1505 & GD1702 & GD0705 & GD0402* \\
\hline Strains GD1209, 1212,0301\# & 0.975 & & & & & & & & \\
\hline Strain GD0302 & 0.928 & 0.923 & & & & & & & \\
\hline Strains GD0403, 0404\# & 0.975 & 0.999 & 0.923 & & & & & & \\
\hline Strain GD1406 & 0.961 & 0.970 & 0.931 & 0.970 & & & & & \\
\hline Strain GD1505 & 0.952 & 0.957 & 0.915 & 0.957 & 0.978 & & & & \\
\hline Strain GD1702 & 0.975 & 0.998 & 0.922 & 0.997 & 0.971 & 0.958 & & & \\
\hline Strains GD0705, 0706\# & 0.967 & 0.964 & 0.930 & 0.964 & 0.964 & 0.952 & 0.964 & & \\
\hline Strain GD0402* & 0.956 & 0.947 & 0.924 & 0.946 & 0.948 & 0.940 & 0.948 & 0.969 & \\
\hline Bacillus firmus & 0.997 & 0.971 & 0.926 & 0.971 & 0.960 & 0.950 & 0.972 & 0.967 & 0.955 \\
\hline Bacillus jeotgali & 0.964 & 0.997 & 0.921 & 0.996 & 0.972 & 0.959 & 0.995 & 0.963 & 0.945 \\
\hline Bacillus sphaericus & 0.929 & 0.924 & 0.991 & 0.924 & 0.932 & 0.917 & 0.923 & 0.932 & 0.926 \\
\hline Bacillus bataviensis & 0.967 & 0.969 & 0.936 & 0.969 & 0.993 & 0.978 & 0.969 & 0.965 & 0.951 \\
\hline Bacillus djibelorensis & 0.964 & 0.967 & 0.934 & 0.967 & 0.994 & 0.979 & 0.968 & 0.964 & 0.951 \\
\hline Bacillus pichinotyi & 0.922 & 0.963 & 0.926 & 0.963 & 0.964 & 0.952 & 0.964 & 0.986 & 0.963 \\
\hline Strain sp90+ & 0.768 & 0.768 & 0.774 & 0.768 & 0.766 & 0.758 & 0.769 & 0.770 & 0.765 \\
\hline
\end{tabular}




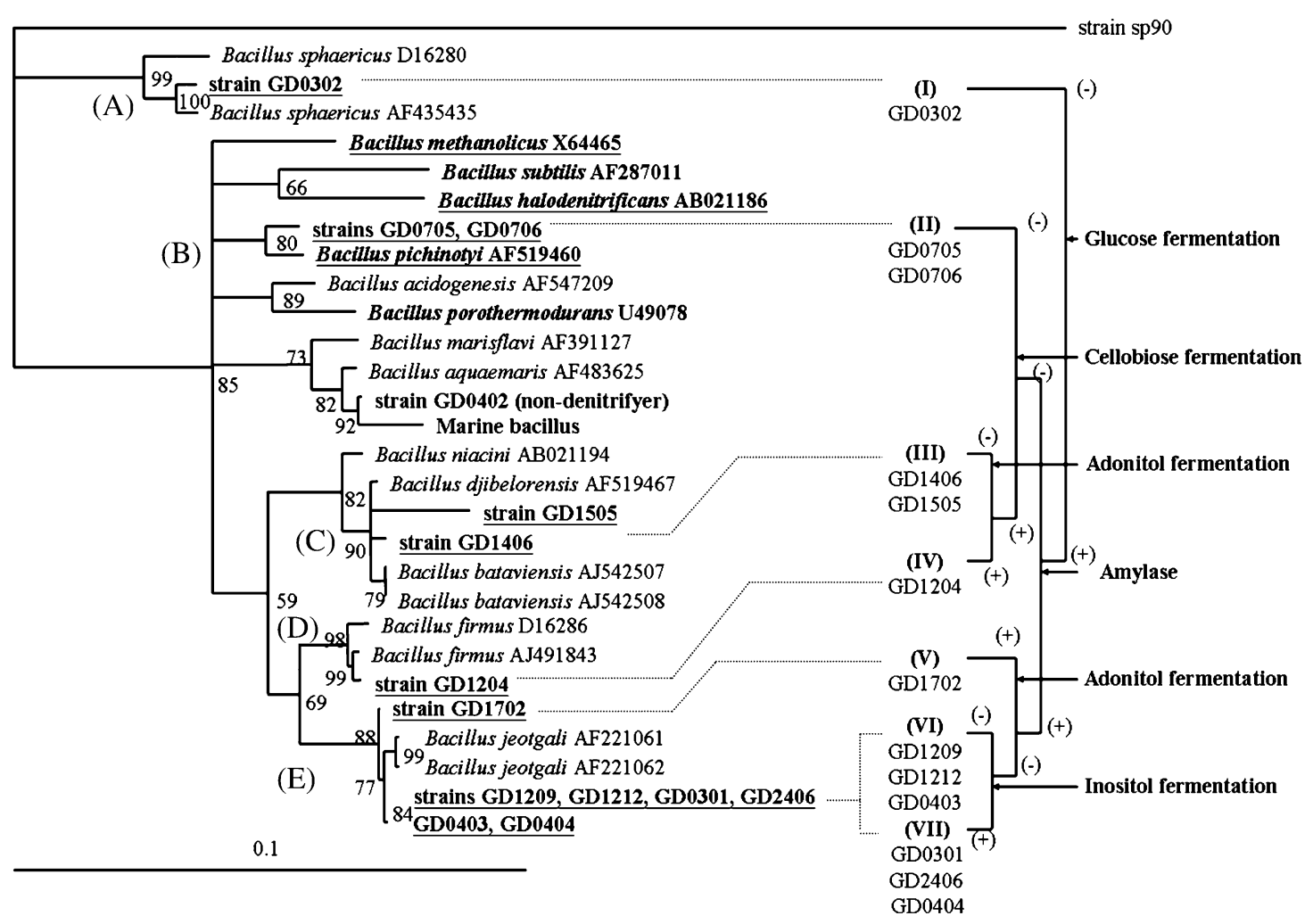

Fig. 3. Phylogenetic (left) and physiological (right) comparisons of denitrifier strains. Underlining indicates a denitrifier strain. Capital letters (A-E) refer to phylogenic clades. Numbers above the nodes represent bootstrap confidence values obtained with 1000 resamplings; values below 80 are not shown. Bar, $10 \%$ estimated sequence divergence. Roman numerals (I-VII) refer to physiological groups. The symbols ' + ' and '-' respectively refer to positive and negative effects of each physiological test.

V, and VI all belonged to phylogenic clade E (Fig. 3). Compared to the environment profile, phylogenic clades A and D (groups I and IV) were restricted to a depth of $1-3 \mathrm{~cm}$ where the concentrations of oxidized compounds (nitrate and sulfate) were the highest. Clade C (group III) appeared at a depth of $5-8 \mathrm{~cm}$, where concentrations of nitrate compounds were lower, but the denitrifiers were most abundant. Clade B (group II) was distributed at a depth of $11-12 \mathrm{~cm}$, where concentrations of reduced compounds (ammonium, AVS, and pyrite) were high. Clade E strains were widely distributed from shallow to deep depths, but were physiologically diverse between the shallow-middle and deep groups.

\section{Discussion}

With the exception of the upper $1 \mathrm{~cm}$ of depth, the general profile of the chemical composition might not vary dramatically during seasonal and tidal changes in the estuarine sediment (Usui et al., 1998). Based on the distribution of nitrogenous compounds and denitrifier abundances, the vertical profile of the Guandu sediments could be separated into four layers (Fig. 4). The upper $1 \mathrm{~cm}$ of depth through the overlying water is called the mixed layer, and levels of salinity, nitrate, and sulfate in its interstitial water were low. The profile from 1 to $5 \mathrm{~cm}$ in depth, called the nitrate-concentrated layer, was characterized by concentrations of nitrate and sulfate which were higher than at other depths. The profile from 5 to $9 \mathrm{~cm}$ in depth, where the concentration of nitrate was low but denitrifier abundance was much higher, was named the denitrifier-aggregation layer. The profile from 9 to $12 \mathrm{~cm}$ of depth, where concentrations of ammonium still increased with depth, was named the ammonium-enriched layer.

\subsection{Distributions of nitrogenous nutrients and denitrifier abundances}

We observed a distinct minimum of salinity in the mixed interface, and subsurface peaks of both nitrate and sulfate concentrations in the nitrate-concentrated layer at low tide in the estuary of the Tanshui River at Guandu. The concentration of sulfate was greater (over 6000-fold) than nitrate in these sediments, because it was mainly from seawater (Capone and Kiene, 1988); however, nitrate was oxidized in the seawater (Jiann et al., 2005). Sulfate could penetrate as deep as seawater, but nitrate was restricted by the oxygen supply or denitrification (Mäkelä and Tuominen, 2003). As salinity decreases towards the freshwater end of the estuary, the contribution of sulfate from seawater declines (Nedwell et al., 1999). However, nitrate, introduced through the river end, did not become increasingly significant in the mixed layer (Fig. 4), like in other hypernutrified estuaries (Usui et al., 1998; Nedwell et al., 1999). Places where nitrate sources are contributed from the overlying water present sharply decreased interstitial nitrate from the sediment-water interface downwards (e.g., in 


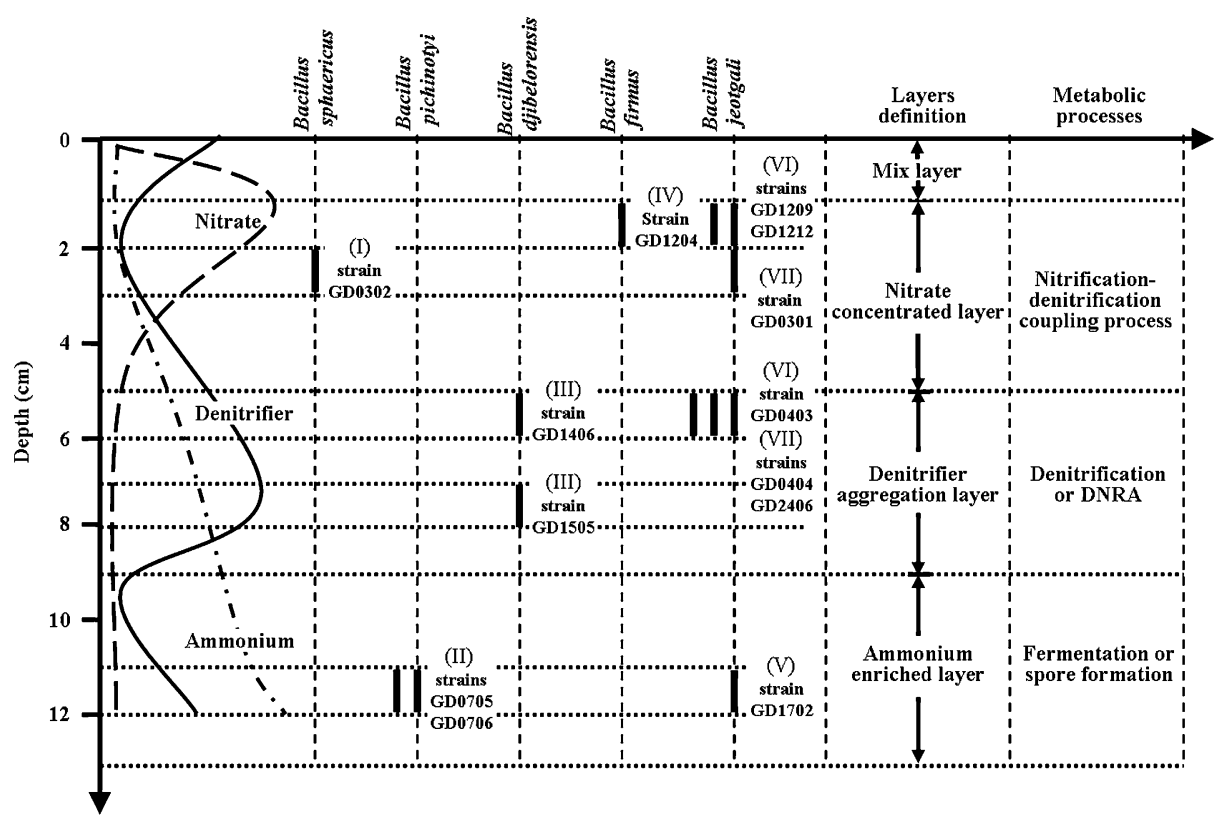

Fig. 4. Summary of the concentrations of nitrate and ammonium, denitrifier abundance profiles, the vertical distribution of denitrifying isolated strains (one bold line for each strain), layer definitions, and corresponding metabolic strategies in the Tanshui River Estuarine sediments. Roman numerals (I-VII) refer to physiological groups. DNRA, dissimilarity nitrate reduction to ammonium.

the estuary of the Tama River, Japan; Usui et al., 1998). A subsurface peak of nitrate concentration as was shown by our results was also observed in sandy sediments with a significant oxic layer (e.g., Nedwell et al., 1999). This subsurface peak results in bidirectional diffusion gradients of nitrate (Nedwell et al., 1999), and the nitrate may be taken up by microbial biofilms and/or actively denitrified (Mäkelä and Tuominen, 2003). Corresponding peaks of denitrifier abundance in both the mixing and the denitrifier-aggregation layers were observed, and well document the denitrifying potential of Guandu sediments (Fig. 4).

Supplies of nitrate in coastal marine sediments appear to be derived almost exclusively from sediment nitrification (e.g., Ogilvie et al., 1997) or direct inputs from rivers (e.g., Usui et al., 1998). Compared to other estuaries with high nitrogen nutrient inputs (Usui et al., 1998; Mäkelä and Tuominen, 2003), the reduced form of ammonium was the predominant nitrogen form at Guandu, and this was due to eutrophic and organically polluted water from reaches upstream of Guandu (Wu, 1999). Nitrate was consistently abundant near the sediment surface where salinities were relatively high in the Guandu sediment (Fig. 4). The ammonium contributed by fresh water declines as salinity increases towards the seawater end of the estuary in the Tanshui River (Jiann et al., 2005). In estuaries with considerable flushing, gravitational and/or tidal circulation can disrupt stratification and replenish bottomwater oxygen in a matter of hours (e.g., Usui et al., 1998). Such relatively high oxygen levels in the water are replenished from the seaward, suggesting that nitrification in the sediments might become the predominant source of nitrate for denitrification in the estuary of the Tanshui River. The supplies of nitrate derived from sediment nitrification with considerable flushing further diffuse into the overlying water in the estuary of the Colne River, UK (Ogilvie et al., 1997), and Rysgaard et al. (1993) indicated that when the nitrate concentration in the water phase was low $(5 \mu \mathrm{M})$, the coupling between nitrification and denitrification accounted for a large fraction (72\%) of the total denitrification in the Norsminde Fjord, Demark. These situations might occur in Guandu sediments due to the relatively low concentrations of nitrate in the estuary of the Tanshui River (Wu, 1999).

The pattern of ammonium in the Guandu sediments was similar to those of other estuaries with high nitrogen nutrient inputs (Mäkelä and Tuominen, 2003), but the concentrations were much higher (up to $2.2 \mathrm{mM}$ ). Ammonium concentrations usually decrease towards the sediment surface because ammonification generates ammonium during mineralization of organic matter, and ammonium therefore diffuses upwards along the concentration gradient (Nedwell et al., 1999). A relatively high organic content in the denitrifier-aggregation and ammoniumenriched layers may support such high ammonium generation by the Guandu sediments. In addition, similar patterns of the TOC and TN content profiles and the relatively high $\mathrm{C} / \mathrm{N}$ ratio (with a range of 10.71-13.79) in organic content further indicated that the anthropogenic discharge at Guandu occurs faster than the sediment can metabolize it (Canfield et al., 2005). The high available carbon supplies, possession of a high $\mathrm{C} / \mathrm{N}$ ratio, and the temperature effect also cause dissimilatory nitrate reduction to ammonium (DNRA) (Nedwell et al., 1999). Relatively high C/N ratios were observed for all sediment profiles at Guandu, and DNRA might be active and serve as another ammonium source in the estuary of Tanshui River.

Unlike other reduced compounds, such as ammonium, AVS, and pyrite, sulfide was only detected at either end at the sediment-water interface and the deepest sampling depth because most of the sulfide was mineralized as insoluble metal 
sulfides (Morse and Richard, 2004). High sulfide concentrations inhibit nitrification and denitrification but may enhance DNRA by providing an electron donor (e.g., in Laguna Madre/Baffin Bay, Texas; An and Gardner, 2002). However, in the sediment milieu, the reduction of trivalent iron is closely coupled to sulfate reduction by the formation of new solid phases such as AVS (FeS) and pyrite $\left(\mathrm{FeS}_{2}\right)$, which can be regarded as temporal sinks for sulfide (e.g., in the estuary of the Seine River, France; Ouddane et al., 2001). Divalent iron acts as a buffer, which prevents free sulfide from accumulating in the sediments (Morse and Richard, 2004). In the Guandu sediments, the amount of sulfide produced by sulfate reduction seemed to closely reflect the accumulation of AVS and pyrite both in the denitrifier-aggregation and the ammoniumenriched layers, whereas the rest might have been incorporated in DNRA in the denitrifier-aggregation layer. These phenomena further indicate that inhibition of nitrification and denitrification by high sulfide concentrations was insignificant in the Guandu sediments, at least in the profile at this sampling depth.

Although MPN counts usually underestimate the actual number of bacteria present, it was possible to get some information on the vertical profile of populations at low tide in the Guandu sediments. After comparing the profiles of both denitrifier abundances and concentrations of nitrate, the greatest abundance of denitrifiers was observed where nitrate was scarce, which documents that a high abundance of denitrifiers limits nitrate being distributed to deeper depths and vice versa (Fig. 4). A decline in denitrification was observed in mangrove soil in the intertidal flat at Guandu, which suggests that the denitrification potential can be implied by the existence of denitrifiers (Chiu et al., 2004). The same pattern of denitrifier abundances was also found for the organic and water content profiles in the denitrifier-aggregation layer. Microbial abundances being positively related to the organic matter and water contents was also observed in a previous study (Weier and MacRae, 1992). These phenomena suggest that both the organic matter and water contents might be the factors influencing denitrifier abundances in the denitrifier-aggregation layer.

Sub-peaks of denitrifier abundances were also observed in both the mixing and the ammonium-enriched layer (Fig. 4). Denitrifier peaks appearing in the mixing layer is simply explained by the nitrate decline to the underlying water and sudden hypoxia. However, denitrifier peaks appeared in the ammonium layer where the nitrate source was scarce but the organic matter was high. This suggests that the denitrifying ability is inactive. Denitrifiers that exist here must utilize some metabolic pathways other than denitrification (Tiedje, 1988; Thamdrup and Dalsgaard, 2002; Shieh et al., 2004), such as fermentation or spore formation.

\subsection{Properties of the denitrifying bacteria}

Denitrifying strains isolated from this study all belonged to the genus Bacillus. Although culturing bias may have underestimated some other denitrifier populations, we can at least say that Bacillus is one of the predominant denitrifying groups in the Guandu sediments. Bacillus species account for nearly $10 \%$ of all denitrifying bacteria in soil environments (Weier and MacRae, 1992), and become the top three dominant species of denitrifier (Zumft, 1992). Compared to formally published strains, most of the strains isolated from Guandu sediments with denitrifying activities are documented here for the first time, such as Bacillus jeotgali, Bacillus sphaericus, Bacillus firmus, and Bacillus bataviensis. Bacillus jeotgalirelated strains, including GD1209, GD1212, GD0301, GD0403, GD0404, GD2406 and GD1702, were widely distributed from the nitrate-concentrated to the ammonium-enriched layer (Fig. 4). Bacillus jeotgali was originally isolated from the Korean traditional food, jeotgal, and is possesses a variety of physiological properties including the ability to reduce nitrates (Yoon et al., 2001). However, no further report has studied its denitrification ability.

Bacillus sphaericus- (including GD0302) and Bacillus firmus-related strains (including GD1204) were only isolated from the nitrate-concentrated layer (Fig. 4). These two related isolates have long been known and have been widely isolated from soil, marine and freshwater sediments, and some foods (Sneath, 1986). Due to the fact that the nitrate-concentrated layer usually appears below the oxygen peak (e.g., Capone and Kiene, 1988; Canfield et al., 2005) nitrification-denitrification coupling might occur in this place (Nedwell et al., 1999). Previous studies suggested that the heterotrophic Bacillus strains possessed less-complex metabolic pathways for removal of ammonia than did autotrophs, and Bacillus strains such as Bacillus cereus, Bacillus licheniformis, and Bacillus subtilis are involved in aerobic nitrificationdenitrification processes in soil treatment systems (e.g., Kim et al., 2005). Although the ability of nitrification was not well defined in this study, Bacillus jeotgali-, B. sphaericus-, and $B$. firmus-related strains might involve the nitrificationdenitrification coupling process in the nitrate-concentrated layer, thus contributing to the denitrifying ability.

Bacillus bataviensis-related strains, including GD1406 and GD1505, were isolated from the denitrifier-aggregation layer (Fig. 4). Bacillus bataviensis was previously isolated from a grassland, and its ability to reduce nitrate is also recognized (Heyrman et al., 2004). However, like Bacillus jeotgali-related strains also isolated here, no further report has studied its denitrification ability. These Bacillus-related strains might be the predominant denitrifying population because of the high abundances of denitrifiers aggregated here (Fig. 4). However, either DNRA or the anammox process might be occurring due to the fact that these related strains are only capable of nitrate reduction as reported in previous studies (Yoon et al., 2001; Heyrman et al., 2004). Based on the fate of nitrite, which is the first intermediate in nitrate reduction, three different pathways can be distinguished: denitrification, dissimilatory nitrate reduction to ammonium (DNRA), and reduction to nitrogen gas coupled to the oxidation of ammonium by the newly discovered anammox process (Thamdrup and Dalsgaard, 2002; Canfield et al., 2005). Bacillus strains such as Bacillus subtilis and Bacillus licheniformis have been observed to possess DNRA ability (Tiedje, 1988), but there are few if any reports 
concerned with Bacillus-related strains involved in the anammox process. In addition, anammox-related strains were not observed in this study. We cannot firmly say that no anammox process occurs in the Guandu sediments, even though this process was found to be insignificant in eutrophic coastal systems by Thamdrup and Dalsgaard (2002).

Strains GD0705 and GD0706, which were isolated from the ammonium-enriched layer, were not closely related to any formally published strains and might be new species (Fig. 4). In addition, this layer where strains isolated lacked nitrate. In the previous section, we discussed how in such a situation, other metabolic pathways might be utilization instead of denitrification by denitrifiers, such as fermentation or spore formation. Fermentation, like denitrification, is a type of metabolism that allows an organism to obtain energy for anaerobic growth (Shieh et al., 2004), especially in the absence of other inorganic electron acceptors (e.g., Canfield et al., 2005). Heterotrophic denitrifiers such as conventional pseudomonads have been shown to be capable of surviving in anaerobic and nitrate-free environments by utilizing low-level fermentation (Shieh et al., 2004). All of the denitrifying strains isolated in this study have fermentative abilities of various carbohydrates. Fermentation processes might replace denitrification as the main metabolic pathway in the ammonium-enriched layer, which further supports such high ammonium abundances $(2.2 \mathrm{mM})$ in the Guandu sediments. In addition to fermentation, all strains isolated in this study were spore-forming bacteria. Spore formation represents a strategy by which a bacterial cell can temporally escape from nutritionally unfavorable local conditions via dormancy (Sneath, 1986). Klobutcher et al. (2006) further reported that the spore coat plays a role in resistance to predation by ciliated protozoa. Thus, whether or not the denitrifying strains had germinated from spores, the spore-forming ability would enhance this kind of denitrifier in the face of such a nitrate-deficient environment.

In conclusion, results of these integrated approaches reveal that various metabolic pathways in similar denitrifying strains occur owing to their physiological acclimations to the biogeochemical properties of nitrogenous mineralization in different sediment layers (Fig. 4). For further studies, different levels of landward/seaward driving forces based on the distance from the river mouth should be investigated by examining horizontal variations in sediment profiles. In addition, the various denitrifying communities appearing in spatial gradients with varied nitrogenous nutrients need to be explored. Whether varieties exhibit complete phylogenic diversity of denitrifiers or simply physiological versatility of similar strains should be clarified in different horizontal and vertical scales of spatial zonation. Moreover, the potential roles of infauna and roots of vegetation influencing the composition of both nitrogenous nutrients and denitrifier strains in the sediment profile should not be overlooked.

\section{Acknowledgments}

We gratefully acknowledge the team of Dr. Hsing-Juh Lin for sediment samples collection and Dr. Saulwoon Lin for sulfurous compounds analyses. We also thank Dr. Shou-Chung Huang and two anonymous referees for valuable comments on the manuscript.

\section{References}

An, S.M., Gardner, W.S., 2002. Dissimilatory nitrate reduction to ammonium (DNRA) as a nitrogen link, versus denitrification as a sink in a shallow estuary (Laguna Madre/Baffin Bay, Texas). Marine Ecology Progress Series 237, 41-50.

Bennasar, A., Guasp, C., Tesar, M., Lalucat, J., 1998. Genetic relationships among Pseudomonas stutzeri strains based on molecular typing methods. Journal of Applied Microbiology 85 (4), 643-656.

Canfield, D.E., Raiswell, R., Westrich, J.T., Reaves, C.M., Berner, R.A., 1986 The use of chromium reduction in the analysis of reduced inorganic sulfur in sediments and shales. Chemical Geology 54 (1-2), 149-155.

Canfield, D.E., Thamdrup, B., Kristensen, E., 2005. Aquatic geomicrobiology. Advances in Marine Biology 48, 1-600.

Capone, D.G., Kiene, R.P., 1988. Comparison of microbial dynamics in marine and freshwater sediments: contrasts in anaerobic carbon catabolism. Limnology and Oceanography 33, 725-749.

Chiu, C.Y., Lee, S.C., Chen, T.H., Tian, G.L., 2004. Denitrification associated $\mathrm{N}$ loss in mangrove soil. Nutrient Cycling in Agroecosystems 69 (3), 185189.

Cline, J.D., 1969. Spectrophotometric determination of hydrogen sulfide in natural waters. Limnology and Oceanography 14 (3), 454-458.

Felsenstein, J., 1989. PHYLIP-Phylogeny Inference Package Version 3.2. Cladistics 5, 164-166.

Heyrman, J., Vanparys, B., Logan, N.A., Balcaen, A., Rodiguez-Diaz, M., Felske, A., De Vos, P., 2004. Bacillus novalis sp. nov., Bacillus vireti sp. nov., Bacillus soli sp. nov., Bacillus bataviensis sp. nov. and Bacillus drentensis sp. nov., from the Drentse A grasslands. International Journal of Systematic and Evolutionary Microbiology 54, 47-57.

Hsieh, H.L., 1995. Spatial and temporal patterns of polychaete communities in a subtropical mangrove swamp-influences of sediment and microhabitat. Marine Ecology Progress Series 127 (1-3), 157-167.

Jiann, K.-T., Wen, L.S., Santschi, P.H., 2005. Trace metal (Cd, Cu, Ni and Pb) partitioning, affinities and removal in the Danshuei River estuary, a macrotidal, temporally anoxic estuary in Taiwan. Marine Chemistry 96 (3-4), 293-313.

Jukes, T.H., Cantor, C.R., 1969. Evolution of protein molecules. In: Munro, H.N. (Ed.), Mammalian Protein Metabolism. Academic Press, New York, pp. 21-132.

Kim, J.K., Park, K.J., Cho, K.S., Nam, S.-W., Park, T.-J., Bajpai, R., 2005 Aerobic nitrification-denitrification by heterotrophic Bacillus strains. Bioresource Technology 96, 1897-1906.

Klobutcher, L.A., Ragkousi, K., Setlow, P., 2006. The Bacillus subtilis spore coat provides "eat resistance" during phagocytic predation by the protozoan Tetrahymena thermophila. Proceedings of the National Academy of Sciences of the United States of America 103 (1), 165-170.

Liu, W.C., Hsu, M.H., Kuo, A.Y., 2002. Modeling of hydrodynamics and cohesive sediment transport in Tanshui River estuarine system, Taiwan. Marine Pollution Bulletin 44, 1076-1088.

Mäkelä, K., Tuominen, L., 2003. Pore water nutrient profiles and dynamics in soft bottoms of the northern Baltic Sea. Hydrobiologia 492, 43-53.

Morse, J.W., Richard, D., 2004. Chemical dynamics of sedimentary acid volatile sulfide. Environmental Science and Technology April 1, 131A-136A.

Nedwell, D.B., Jickells, T.D., Trimmer, M., Sanders, R., 1999. Nutrients in estuaries. Advances in Ecological Research 29, 43-92.

O’Dell, J.W., Pfaff, J.D., Gales, M.E., McKee, G.D., 1984. Method 300.0: The determination of inorganic anions in water by ion chromatography. Environmental Protection Agency, Cincinnati, OH, USA.

Ogilvie, B., Nedwell, D.B., Harrison, R.M., Robinson, A., Sage, A., 1997. High nitrate, muddy estuaries as nitrogen sinks: the nitrogen budget of the River Colne estuary (United Kingdom). Marine Ecology Progress Series $150,217-228$. 
Ouddane, B., Boust, D., Martin, E., Fischer, J.C., Wartel, M., 2001. The postdepositional reactivity of iron and manganese in the sediments of a macrotidal estuarine system. Estuaries 24 (6B), 1015-1028.

Pai, S.C., Riley, J.P., 1994. Determination of nitrate in presence of nitrite in natural water by flow injection analysis with a non-quantitative online cadmium reductor. International Journal of Environmental Analytical Chemistry $57,263-277$.

Pai, S.C., Tsau, Y.J., Yang, T.I., 2001. PH and buffering capacity problems involved in the determination of ammonia in saline water using the indophenol blue spectrophotometric method. Analytica Chimica Acta 434 209-2160.

Rysgaard, S., Risgaard-Petersen, N., Nielsen, L.P., Revsbech, N.P., 1993. Nitrification and denitrification in lake and estuarine sediments measured by the ${ }^{15} \mathrm{~N}$ dilution technique and isotope pairing. Applied and Environmental Microbiology 59, 2093-2098.

Shieh, W.Y., Simidu, U., Maruyama, Y., 1989. Enumeration and characterization of nitrogen-fixing bacteria in an eelgrass (Zostera marina) bed. Microbial Ecology 18, 249-259.

Shieh, W.Y., Lin, Y.T., Jean, W.D., 2004. Pseudovibrio denitrificans gen. nov., sp. nov., a marine, facultative anaerobic, fermentative bacterium capable of denitrification. International Journal of Systematic and Evolutionary Microbiology 54, 2307-2312.

Sneath, P.H.A., 1986. Endospore forming gram-positive rods and cocci. In Sneath, P.H.A., Mair, N.S., Sharpe, M.E., Holt, J.G. (Eds.), Bergey's Manual of Systematic Bacteriology, vol. 2. Williams and Wilkins Press, Baltimore, MD, pp. 1104-1207.
Thamdrup, B., Dalsgaard, T., 2002. Production of $\mathrm{N}_{2}$ through anaerobic ammonium oxidation coupled to nitrate reduction in marine sediments. Applied and Environmental Microbiology 59 (3), 1312-1318.

Thompson, D.B., Ravussin, E., Bennett, P.H., Bogardus, C., 1997. Structure and sequence variation at the human leptin receptor gene in lean and obese Pima Indians. Human Molecular Genetics 6 (5), 675-679.

Tiedje, J.M., 1988. Ecology of denitrification and dissimilatory nitrate reduction to ammonium. In: Zehnder, A.J.B. (Ed.), Biology of Anaerobic Microorganisms. Wiley, New York, pp. 179-244.

Usui, T., Koike, I., Ogura, N., 1998. Tidal effect on dynamics of pore water nitrate in intertidal sediment of a eutrophic estuary. Journal of Oceanography $54,205-216$.

Weier, K.L., MacRae, I.C., 1992. Denitrifying bacteria in the profile of a brigalow clay soil beneath a permanent pasture and a cultivated crop. Soil Biology and Biochemistry 24 (9), 919-923.

Wu, J.T., 1999. A generic index of diatom assemblages as bioindicator of pollution in the Keelung River of Taiwan. Hydrobiologia 397, 79-87.

Yoon, J.-H., Kang, S.-S., Lee, K.C., Kho, Y.H., Choi, S.H., Kang, K.H., Park, Y.-H., 2001. Bacillus jeotgali sp. nov., isolated from jeotgal, Korean traditional fermented seafood. International Journal of Systematic and Evolutionary Microbiology 51, 1087-1092.

Zumft, W.G., 1992. The denitrifying procaryotes. In: Balows, A., Trüper, H.G., Dworkin, M., Harder, W., Schleifer, K.H. (Eds.), The Prokaryotes, vol. 1. Springer Verlag Press, New York, pp. 554-582. 